\title{
Learning Objects, Learning Object Repositories, and Learning Theory: Preliminary Best Practices for Online Courses
}

\author{
Susan Smith Nash \\ Excelsior College, Albany, NY, USA
}

susan@beyondutopia.com

\begin{abstract}
This paper evaluates current practices in the use of learning objects in online courses, reviews best practices, and suggests new approaches that incorporate learning theory. In doing so, the paper also explores the relationship between the use of learning objects and learning theory. The analysis and observations are based on surveys of existing approaches, best practices, and handson experience. Placing the use of learning objects within the context of constructivist epistemologies is seen as pivotal to understanding how to effectively use them within online courses. In addition, it responds to the challenge of the eclectic epistemology that confronts the instructional designer, the e-learner, and the facilitator, and it provides a method for using learning objects to overcome ambiguity and barriers to student persistence in a distance learning setting. The paper discusses how to apply motivation theories to the use of learning objects and how doing so can help learners achieve outcome goals. Further, the paper addresses learner needs and limitations and discusses how learning objects can be deployed in a way that maximizes accommodation and flexibility. It discusses cases of successful and unsuccessful uses of learning objects in online learning, and proposes guidelines for best practices.
\end{abstract}

Keyword: Learning objects, learning theories, repositories, online courses

\section{Introduction}

In the broadest sense, a learning object is anything that has an educational purpose (McGreal, 2004). In the case of an online course, it is a given that a learning object is a digital object that is used in order to achieve the desired learning outcomes or educational objectives.

Although the term, "learning object" originated from the notion of "object-oriented" computing and programming, which suggests that ideal way to build a computer program or anything digital is to assemble it from standardized, small, interchangeable chunks of code, the approach is somewhat different in an e-learning setting. In this case, learning management systems (LMS), of

Material published as part of this journal, either on-line or in print, is copyrighted by the publisher of the Interdisciplinary Journal of Knowledge and Learning Objects. Permission to make digital or paper copy of part or all of these works for personal or classroom use is granted without fee provided that the copies are not made or distributed for profit or commercial advantage AND that copies 1) bear this notice in full and 2) give the full citation on the first page. It is permissible to abstract these works so long as credit is given. To copy in all other cases or to republish or to post on a server or to redistribute to lists requires specific permission and payment of a fee. Contact Publisher@ijklo.org to request redistribution permission. which popular commercial ones are BlackBoard, WebCT, and Desire2Learn, could be considered large meta-objects, that contain spaces for the incorporation of granular objects.

The analogy that is often used to describe this is that of LEGO ${ }^{\mathrm{TM}}$ building blocks. The building blocks have a standard shape and configuration, but they can be used and put together in many ways, to create unique entities, 
limited only by the imagination (and good planning).

Downes (2005) and Leslie (2005), along with other writers have focused on the need to create objects of sufficient granularity to assure effective implementation across multiple courses. In the UCB Wiki, Leslie (2005) described the contexts of sharing of learning objects, and categorized them as sharing, multi-purposing, and repurposing. Siemens (2003) focused on the importance of developing taxonomies and systems for organizing and retrieving content in the form of learning objects.

By housing interchangeable objects on a server and allowing multiple and simultaneous access via the Internet, instructional designers and instructors can access the objects simultaneously and incorporate them into their programs.

Ironically, this is not always the case in actual practice, even when SCORM compliancy is required. The learning management system, which functions as a relational database, integrating instructional material along with administrative, may actually block the use of sharable content objects, depending on what they are, and what information they contain.

The other exception to this is the increasing adoption of blogs and podcasts as e-learning objects. These can be as granular as their RSS feeds, which is to say that they're not very granular at all, because they must be used in conjunction with the codes and third-party services that syndicate, distribute, classify, and house them.

\section{Location of Learning Objects for Use in E-Learning}

In the mid-1990s, relatively simple learning objects were made available informally, as instructors shared syllabi, lesson plans, and learning activities. Later, more complex and/or topicspecific repositories came into existence as museums, journals and magazines, educational television, and other organizations placed content on the web and encouraged it to be used for educational purposes. Many even developed learning activities around the objects, (thus creating a larger, "second-order" learning object) and made them available via download from their websites.

Later, sites dedicated themselves to making learning objects from all disciplines. Instead of housing the objects on their own servers, they often linked to the original sites where the objects were made available. Large repositories of learning objects are now available from MERLOT, CAREO, and Wisconline, among others. Although this tactic offers greater access and availability, they are not always easily navigated, nor is there a uniform system for classifying them, although several projects are underway.

Examples of repositories of learning objects for use in specialized training include the aviation industry and its AICC (Aviation Industry Computer-based Training Committee), that helps set standards. Other industry and military issues are dealt with by such initiatives as the NMC Learning Object Initiative (http://www.nmc.org/projects/lo/gtso.shtml). NMC, the New Media Consortium, is an international 501(c)3 not-for-profit consortium of approximately 200 colleges, universities, museums, corporations, and other learning-and education based organizations that use new media and new technologies.

Wikis: The term used to describe a shared media repository, wiki, derives from the Hawaiian word, "wiki-wiki" for "quick" or "informal." (http://www.wikipedia.org) In a broad sense of the word, the entries could be considered learning objects. In practice, wiki entries do serve educational functions, and many online courses link to wiki entries to provide definitions and perspectives on the subject being studied.

Serious Games: Video game-based simulations or "serious games" have been incorporated into both online and hybrid courses. These are rarely hosted on the educational institution's server; 
instead, the individual learner downloads the program and runs it in accordance with the instructions given in the course. Some allow collaboration and role-playing in a manner that involves a large number of players or users. Social Impact Games (http://www.socialimpactgames.com/) has identified and classified more than 500 "serious games," many of which are available for free download and play. Their goal is to identify video game-based simulation and serious games that have connections with current global and local social issues.

Weblogs: Weblogs, or "blogs," constitute informal repositories of learning objects in two ways. First, the "blog roll," or list of related or recommended blogs helps one become acquainted with other blogs. The blogs in the blogroll can, in fact, be considered learning objects when utilized for an educational purpose. Aggregators of blogs that bring together excerpts of posts from blogs by means of syndication (RSS) also could be considered informal repositories of learning objects.

Podcasts: Podcasts, are mp3 files that are managed and distributed in much the same way as blogs, so they may also be considered informal learning object repositories. Instead of being textbased, these files are audio files, and they are downloaded through the Internet and played on $\mathrm{mp} 3$ players. The originating host usually maintains an inventory of the $\mathrm{mp} 3$ files which can be accessed through syndication and other audio feed services.

\section{Proposed Best Practices for Using Learning Object Repositories}

Learning object repositories, or "LORs," can be difficult to navigate, and the object difficult to integrate into one's online course. Although LORs are new, researchers such as Jochems, Van Merrienboer, Koper, \& Van Merrienboer (2003) and McLaren (2004) have written on how to best how and use learning objects that are stored in digital repositories.

A few of the larger learning object repositories that encourage downloading and sharing of resources include the following:

- Campus Alberta Repository of Educational Objects (CAREO). Comprised of 5,000 multidisciplinary teaching materials, the database is searchable, and the collection is webbased. This Canadian project has been recognized as a leader in the LOR initiative. http://www.careo.org

- Federal Government Resources for Educational Excellence (FREE). This contains numerous educational resources, which include teaching ideas, instructional activities, photographs, maps, audio files, digitized paintings, lesson plans. http://www.ed.gov/free

- FreeFoto.com This is one of several repositories that contain high-quality photographs for educational as well as commercial use. http://www.freefoto.com

- Maricopa Learning Exchange. This is a digital repository that contains more than 700 learning "packages" which include plans, ideas, samples, and resources.

http://www.mcli.dist.maricopa.edu/mlx

- Merlot. Supported by a consortium of colleges, universities, and state systems, the digital resources are free and open to any users. Designed for higher education, the database includes links to more than 10,000 online learning materials, many with peer reviews, assignments, and ratings. http://www.merlot.org

- Wisconsin Online Resource Center. This digital repository contains more than 1,000 learning objects which are categorized for uses within certain higher education curricula. The image categories include business, general education, English as a Second Language, health, professional development, adult basic education, technical courseware.

http://www.wisc-online.com 


\section{Problems in Implementation}

Faculty and instructional designers encounter problems when they try to adapt learning objects for delivery in their general education college-level distance courses that are intended for a military audience. One result is disappointment and frustration in those who believed in the promise of learning objects to save time, to provide robust solutions with depth, high quality, and to perfect interchangeability.

When searching for "learning objects," one is likely to encounter a vast array of terms and ways to describe them. Terms include knowledge objects, educational objects, knowledge chunks, digital objects, digital educational computer programs, and Flash-exercises.

Once one has untangled the nomenclature problem, one can go to the various repositories. Repositories can look like directories, with large databases that link out to the actual location of the object. Other repositories have a search function that allows one to go out and retrieve objects from archives they maintain on their own servers.

Initiatives at Stanford University (CA) have revolved around finding ways to share software that allows collaborative classification, hosting, and access of content. One approach involves creating a system that allows universities to download open-source software that enables them to collect, store, preserve, archive, and deliver content. Although the content that is envisioned consists largely of electronic journals, it could be extended to include all kinds of digital content used in education.

The program, dubbed LOCKSS, which is an acronym for "Lots of Copies Keep Stuff Safe," attempts to avoid the problem of centralization (Villano, 2005) by creating an automated process by which copies are created and downloaded into decentralized servers of participating institutions.

Problem 1 - Not really interchangeable: Because the objects are not of consistent size, nor are they written in consistent languages, they are not really interchangeable in the way that you'd think they'd be. Some are interactive, and others simply consist of text. They can be in html, flash, java, and java-script. Others can be in audio, media, synched PowerPoint, movies, requiring players or internal "jukebox" players.

If one is developing a course for online delivery, sometimes the easiest way to incorporate the object is to link to it. However, there are many problems associated with that strategy - links go down, students may not have the right drivers, plug-ins, etc. Worse, the object itself might "almost" fit one's need, but may not.

Many objects are culturally-inflected, which is to say that they may not be appropriate at all for diverse learners in remote settings, which definitely characterizes military learners.

Problem 2 - Can't find them (lack of consistent classification schemes): Many initiatives have focused on the need to develop a classification scheme, and to catalogue the objects so that individuals can retrieve them, and organizations can archive them. The other issues - learning level (K-12 through graduate) are not resolved in a consistent way. Nor are the points of authorship, copyright, language of the object, etc.

Problem 3 - Quality is highly variable, despite the attempts of some to institute peer review, or quality criteria: MERLOT, CAREO, and others repositories have put together an extensive peerreview approach. Commercial developers have developed systems of quality assurance. However, these are not consistently applied in the production, classification, and/or guide to use of the objects.

Quality and usability issues can often be resolved if designers, technologists, faculty, and subject matter experts are trained in modifying learning objects. This is an excellent solution, but a 
source of deep frustration, due to the fact that the process is time-consuming and there is no guarantee of successful incorporation of the object into the course or learning application.

\section{Suggested Best Practices}

1. Classify by suggested use. It can be difficult to determine how to use them.

2. Classify using as many tags as possible. Because learning objects can be used in "off label" manners, it is good to use as many tags as possible. Otherwise it will be difficult to find the "object" you need.

3. Maintain access to the learning objects. If possible, house them on your own server. If they are a link to an object on someone's website, the link could be dead. If you're using it in CD-ROM or for PDA-delivery, they can be useless.

4. Cross-reference other repositories. Because the repositories are not centrally housed, nor are they maintained by the same groups, there may be gaps. The repositories do not refer to each other and do not cross-catalogue. There is redundancy, inconsistency, and they are often out of date. One way to avoid this would be to standardize meta-tags or classification schemes, and to find a way to search several repositories at the same time.

5. Start small. Instead of trying to classify all learning objects everywhere, it is often best to identify niche users and to build repositories centered around similar objects and users.

6. Standardize as much as possible. This also involves being open to new suggestions, and to maintain a willingness to explore new types of classification schemes and informal indices, such as furls.

7. Maintain open communications and communicate frequently. It is also important to designate a "point person" for questions, clarification, and discussion of alternative classification schemes. For example, folksonomies have emerged as a way to allow individuals to classify, collaborate on, refer to, and house objects. A"folksonomy"can be defined as collaborative classification, which allows individuals to add key words, and to search by key words (rather than hierarchies), has become popular. McClellan (2004) reported on developments in classification, suggesting that folksonomies are powerful because they are "social bookmarks" where the owners of a repository of objects classify them in accordance to their own ideas. Users are not compelled to follow the original owner's schemata, but can assign their own labels according to would be most effective for future retrieval. Developing a "folksonomy" is a kind of tagging, which incorporates notions from anthropology about how individuals informally create systems of classification and meaning. Within the Worldwide Web, "folksonomy" providers include deli.cio.us (http://del.icio.us) and furl (http://www.furl.net), and Flickr (http://www.flickr.com), a digital photo organizing and sharing service. Others do not agree with the folksonomy approach and take other route. Projects such as Stacy Zemke's Living Taxonomy Project (http://www.livingtaxonomy.org) have the goal of not only developing a standard nomenclature and classification system for learning objects, but also for the learning environment itself.

8. Participate in collaborative digital library systems that use industry-standard opensource software. There are many ways to classify digital objects usable in online learning, and while the collaborative approaches of folksonomies can be very effective in identifying key words, they may not be complete and may leave gaps. Further, it can be useful to participate in the open-source initiatives to participate in the process.

9. Resolve intellectual property issues beforehand, and provide clear revenue-sharing or royalty distribution models. While there is still a great deal of material that is free, there is an increasing amount that requires a fee for use, or a licensing arrangement. It is 
important for all parties to be in agreement at the outset, rather than trying to retrofit an arrangement after the fact. Many individuals are availing themselves of Creative Commons licensing to protect their rights, and to encourage limited sharing.

\section{Factors Determining Usability of Learning Objects}

Relevance: For a digital object to be effective in an online course, it must be relevant to the course content, and must materially contribute to the achievement of outcomes.

Usability: The digital object should be usable in the platform or delivery system in use, and it must be accessible by the users.

Cultural appropriateness: The digital object should be appropriate culturally, and the meanings that it communicates within a cultural context should reinforce learning objectives.

Infrastructure support: Objects, whether large or small, simple or complex, should be housed and delivered on a system that is sufficiently robust to handle surges in traffic, bandwidth usage, and storage of large files. It is often necessary to look at solutions such as "edge" computing, which means housing the material on multiple servers.

Redundancy of access: It is important to make digital objects accessible through more than one means of delivery. For example an mp3 audio object could be delivered via Podcast, RSS, or direct download via link.

Size of object: Large objects are sometimes unusable if the users are distributed in remote location where access is poor and/or slow. Optimizing the size of the object, particularly images and audio files is important. For example, using mp3 files instead of wav files can help save space and lead to a more cost-effective solution.

Relation to the infrastructure / delivery: If the object is easily integrated into the learning management system, it is treated differently than a large, complex object (a game, for example), that might be run in conjunction with the learning management system. It may be necessary to modify the delivery system and/or rationale.

\section{Selection of Learning Object Influenced by Course Delivery Method}

1. Online: If the course is delivered using a learning management system such as Desire2Learn, Blackboard, WebCT, etc., it is often important that the learning object have a small size (under 100k) and that it resides in a sharable content file in order to keep from having to replicate it multiple times.

2. CD-ROM or DVDs: Large and complex learning objects, such as video game-based simulations, movies, interactive voice recording (language acquisition) may be best delivered in a CD-ROM or DVD format, particularly if connections are slow and it is not necessary to have simultaneous multi user access.

3. PDA: Interactive (BlackBerry, Palm Pilot) or noninteractive (handheld computer, such as Dell Axim): Large or complex objects requiring Flash, shockwave, java applets, or other plug-ins will not work in most PDA environments. Thus, learning objects must be developed so that they can be translated into the software program used by most mobile computer / handheld environments. This could include MS-Word and MS-Powerpoint for palms or mobile computing. 
4. Hybrid / Blended: Because of the flexibility of the blended solution, it is often possible to utilize many different types of learning objects, ranging from small digital images to rich multimedia and video game-based simulations.

\section{Learning Objective Effectiveness}

Learning object effectiveness is a function of the flexibility of the instructional designer, the intended use, and how central the object is to achieving learning objectives. Some learning objects are really very useful and easy to use. These include interactive grammar reviews for written language acquisition, writing skills development.

Others are very important for achieving learner self-efficacy and self-regulation, as well as improving motivation - for example, interactive maps (of geographical features, the body, animals, etc.) can be engaging, informative, and easy to use. Other examples include interactive dictionaries, and virtual museums that connect the images, background, descriptions, and sources for research.

\section{Learning Objects and Motivation Theories: A Segue to Best Practices}

Learning objects, when incorporated into an online course in an outcome-focused and learnercentered manner, can enhance learner motivation.

Cognitive Evaluation: Deci (1975) and Deci, Vallerand, Pelletier, \& Ryan (1991) conducted research that led them to conclude that cognitive evaluation plays an important role in an individual's belief about whether or not he or she can succeed in a task. Before engaging in a task, individuals analyze it in order to determine whether or not they have a high probability of success. If they predict success, they are likely to embark on the task, and are likely to be motivated to complete the task (high persistence probability).

Learning objects should be developed with the abilities and levels of the users in mind. Mastering the tasks builds confidence and increases self-concept. If not, the users / learners will be frustrated and demotivated.

A good example of how learning objects can be effectively aligned with user grade or skill levels can be found in The ChemCollective's (http://www.chemcollective.org/) virtual chemistry lab activities. All activities are rated on a scale of 1-5 for difficulty, which should help instructors determine which are useful for introductory chemistry courses, and how they might correlate with readings. Although the virtual chemistry has won many awards and has been recognized by MERLOT with an "Editor's Choice" commendation, it is still difficult to replicate the excitement of working with chemicals and seeing the reactions "in vivo." The ChemCollective is a part of the National Science Digital Library (http://nsdl.org/) and has been funded by Carnegie Mellon.

Consistency Theory: Festinger (1957) explored how individuals become demotivated when there is a lack of consistency of behavior, values, and belief, and that such a condition can result in cognitive dissonance. Inconsistency in online learning occurs when instructor behavior does not align itself with expectations, or when the learning objects do not function in a predictable, practical way. For example, the form and function of interactive quizzes can differ from unit to unit, which results in frustration and failure to persist.

Making certain that the learning object uses terminology and instructional strategies that are consistent with those of the online course, and that they are congruent with the texts used is very important. An example is the "Negative Reinforcement University"

(http://www.mcli.dist.maricopa.edu/proj/nru/nru web.html) which was developed by $\underline{\text { Scottsdale }}$ 
Community College students and psychology instructor Bernie Combs, working in conjunction with the Studio 1151 project. The online version was authored by Alan Levine of Maricopa Community Colleges. An extended virtual experience in behaviorism and operant conditioning, the learning object is careful to ground itself in commonly accepted terms, approaches, and terminology, as well as providing a theoretical base that is likely to reinforce what is being read in the course text.

Alan Levine's blog (http://jade.mcli.dist.maricopa.edu/cdb) contains links to other types of activities that can lead to collaborative learning objects, such as wikis.

Goal-Setting Theory: Tetlock and Kim (1987) investigated how individuals are motivated by goals, and the achievement of goals. The key to achieving a goal is to set one that has the following attributes: attainable and accessible. In order to direct ourselves we set ourselves goals that are: Clear (not vague) and understandable; Challenging, to assure stimulation and avoid boredom; and, Achievable, to minimize the chance of failure. Learning objects should be selected so that they can be incorporated in the learner's goal-setting system. For example, required work should be designed so that a student perceives it as achievable. Learning object-driven instructional activities should be clear and easy to conceptualize, but also challenging enough to maintain intellectual engagement.

Goal-setting that integrates a learner's personal financial goals as well as helping attain his or her academic goals can lead to multi-pronged motivation. For example, a personal goal may involve home ownership and personal financial security. A student who is taking an economics or finance class may be very interested in making connections from abstract concepts or case studies to his or her own life. The relevance can be motivating.

In addition, a two-pronged approach to goal-setting could make the online learning object doubly effective. First, the instructional activity may involve goal-setting in terms of time on task, tasks accomplished, along with learning objective and outcome goals. Second, the learning object could provide the learner tools to help decision-making in his or her own life. The National Council on Economic Learning has created a robust array of learning objects which can be woven into an online course. For example, the EconEdLink series of lessons provides a unit entitled "Buying vs. Renting"

(http://www.econedlink.org/lessons/index.cfm?lesson=MM162\&page=teacher ). Part of its "Millionaire Minute" series, the unit helps learners acquire the analytical skills they need to both pass tests and to make sound financial decisions in their own lives.

Affiliation Needs: McClelland (1975) and McClelland and Burnham (1976) discussed how power, affiliation, and achievement are basic motivators. In an online environment, affiliation needs are often satisfied by means of an interactive discussion board or chat area. Instant messaging also often satisfies that need. Any learning object that helps improve collaboration and interactivity among learners is likely to help a learner or user achieve affiliation needs. Further, any learning object that encourages learners to want to identify with the identity of the institution, and to improve self-concept through affiliation is also likely to increase an individual's sense of power and achievement.

List-serves, if not abused, can be an excellent way to share and disseminate learning objects. Communities of practice can form around the use of learning objects, and individuals can share methods of implementing them and incorporating them in courses. For example, the Getty $\mathrm{Mu}-$ seum's education site (http://www.getty.edu/education/) offers a robust education program on their website, which includes lesson plans and art objects. In addition, the education staff could host a list-serve for sharing information, providing new insights into effective instructional strategies, and the use of new technologies. 
Stephen Downes (2005) discusses the way that instructional designers are reconceptualizing how to incorporate learning objects. He discusses collaborative approaches, which also reinforce affiliation needs as they develop communities of practice. In addition, he asks the reader to reconsider how we relate instructional strategies to what we now are coming to understand about the intersections of cognition, linguistics, behaviorism, and other theories.

Self-Actualization: Maslow (1943) created his highly influential hierarchy of needs (Maslow's hierarchy), with basic food and shelter needs at the bottom, and self-actualization at the top. Alderfer (1972) expanded and streamlined Maslow's Hierarchy into the following: Existence, Relatedness and Growth (hence 'ERG'). Instead of a hierarchy of needs, Alderfer maintained that they were a continuum of needs. All needs in Alderfer's equation hinge upon the notion of selfconcept, and the basic core idea that anything that helps an individual develop a better sense of self will be motivating.

An example of a learning object that helps a student imagine herself as a concert pianist, and in control of a repertoire of baroque music can be found in the gorgeous resource, "The WellTempered Clavier: Johann Sebastian Bach: Thirty-Seven Fugues and Select Preludes" by T. Smith and D. Korevaar (2002).

Role-playing can also be used to foster an improved self-concept and to make progress toward self-actualization. In this case, a video game-based simulation could be considered a complex learning object. Nash (2005) writes that "video game-based simulation can be extremely effective in courses that involve "social impact" types of courses, particularly when learning objectives involve equipping the students to be able to practice decision-making skills, problem analysis, and cause-and-effect relationships. For example, courses in economic development, globalization and its local impacts, or community development could incorporate the following "serious games." They could be implemented as individual player games, or as multiplayer games -- even massively multiplayer games (MMORGs)" (Nash, 2005).

For learning objects, it is important to utilize them to reinforce notions that a learner might hold about himself or herself, such as, "I am a successful student," or, "I accomplish tasks in a timely manner, and I do it effectively."

Learning objects can help the learner self-actualize with respect to the subject matter and skills included in the learning activities of the distance-delivered course. At the same time, they can help self-actualization in terms of technology by helping gain a sense of mastery in multiple modes: via personal computer-based online programs, mobile learning (handhelds, both interactive and non-interactive), video game-based learning programs, audio (mobile mp3 players such as iPods), and video.

Distributed Self-Actualization - Blogs and Podcasts: Courses that encourage creative selfexpression and collaborations lend themselves nicely to learning objects distributed by means of blogs and, in the case of audio files, by means of podcasts. In these cases, students are often motivated by the possibility of self-actualization. Because the activity occurs in a distance environment, and the collaboration teams are separated by time and space, the self-actualization process is distributed. For example, a course in writing memoirs or autobiography could post their work in text form, along with appropriate graphics, then add a podcast. Suggestions, collaborations, and revisions could be done collaboratively, either in segments, or with the full item.

\section{Best Practices for Instructional Design using Learning Objects}

Before using a learning object, learning objectives, desired learner outcomes (performative and measurable), range of content and learner level, and instructional strategies must be in place. 
1. Keep motivation theories in mind when selecting objects. If learning objects are selected without keeping in mind certain theories about how humans are motivated, or demotivated, the courses that incorporate them are likely to be ineffective.

2. Align outcomes with instructional activities that incorporate learning objects. Learning Management Systems and learning objects. It is important to review how the object is intended to be used, how it is used in actual practice. In addition to assessing the learners to gain an appreciation of their values, needs, and interests, it is also important to articulate how the learning objects are intended to be used, and how their use will affect outcomes. Then, after the course is deployed, it is important to conduct a post-course review to see how the objects were actually used, and what kinds of outcomes were achieved.

3. Resolve potential technological issues: In addition, all the technological issues must be worked out. What platform will be used? Will a learning management system be used? Will this be a live web-based course? What kinds of access will the students have? Will it be offered in CD-ROM format? Will you use PDAs or hand-held computers? These have to be considered because it is very difficult to retrofit an object once it is incorporated into a learning module.

4. Maintain multiple delivery modes: Online, blended, mobile, video game-based simulation. Because of the increasing need to deliver courses across multiple modes, it is important to design objects so that can be reused or easily repurposed for the modes the learner will be using, and for the actual conditions of delivery. A needs assessment is important for this.

5. Remember real user capabilities and needs. Learning objects vary in size, use, and complexity. Some, such as virtual chemistry labs, require an extensive repertoire of skills, and the ability to work within a number of plug-ins. Others, such as maps or simple images, are static and very easy to use. Although these are easy to use and download, they may not be appropriate if the learner is using a small screen hand-held computer.

6. Sociological Factors. Understanding the cultural beliefs and values is critical in developing an instructional strategy that uses learning objects. It is important to understand the values and how one might unintentionally offend a learner. It is also important to understand cultural values in order to use objects in a way to reinforce self concept and to motivate.

7. Psychological Factors. Motivation, self-concept, self-efficacy, and basic beliefs about how the mind makes meaning are very important. It is also to understand how learning objects can make connections between the learner's experience and the concepts presented in the course in order to achieve learning goals. Learning objects can (if utilized properly) be effective ways to enhance learner self-efficacy and self-concept, as well as to improve learner self-regulation in the quest for effective, flexible, and adaptable learning strategies.

8. ADA compliancy. This is very critical for implementing learning objects, particularly for users with low vision, low hearing, or cognitive needs.

\section{Learning Objects and Constructivist Epistemologies}

Radical constructivism is what psychologist Ernst von Glaserfeld has characterized as a radical "theory of knowledge in which knowledge does not reflect an objective, ontological reality but exclusively an ordering and organization of a world constituted by our experience" (von Glasersfeld, 1984, p.24). However, the question that instructional designers often face is that of limited experience or experience that is unshared by the diverse group of learners in a course. Further, in 
implementing learning objects, it is important to keep in mind that the learners may have shared experiences, but their contexts are different and their perception may be different.

Social constructivism is much more palatable for most instructional designers who are attempting to integrate learning objects into their online or hybrid courses. It suggests that reality is an agreed-upon construct, gradually negotiated or mediated by a group. It has been explained by some that social constructivism "sees consensus between different subjects as the ultimate criterion to judge knowledge. "Truth" or "reality" will be accorded only to those constructions on which most people of a social group agree" (Heylighen, 1993 p.2).

In e-learning, invoking collective shared experience and establishing connections is often easier said than done. The e-learning space is often either too ambiguous or too rigid and overly defined. There can also be too much structure, or a lack of structure.

\section{Conclusion}

Change in the area of distance learning is rapid, and without a solid connection with underlying learning theories, the use of learning objects quickly becomes a function of the technology rather than the desired learning outcome.

To maintain effectiveness requires a proactive attitude, and a willingness to experiment by incorporating learning objects in a number of different modes and contexts. However, before implementing learning objects, it is important to develop a learning strategy which connects the desired learner outcomes and content with underlying theories.

As learning objects continue to evolve and new uses are found for them within online courses, it will be necessary to utilize a standard taxonomy/classification scheme. The need for this is urgent, because without it, learning object repositories will never be able to fully realize their mission of making learning objects available, easily retrievable, and sharable.

Practical approaches should be developed in order to meet these challenges. Perhaps the most efficient and cost-effective approach is to develop and implement preliminary best practices for both the use of learning (or, digital) objects in e-learning, but also for the use of learning object repositories.

Best practices that take into learning theory and behavioral psychology, including motivation, have a higher likelihood of success. Because the objects, course content, and approaches are constantly changing, it is important to assess and review best practices on a regular basis, and make sure they align with desired learning outcomes, and user needs.

Future research is needed to test the efficacy of the use of learning objects such as podcasts within formal and informal instructional activities. Research is also needed to determine the relationship between various objects and learners' motivation, self-concept, self-efficacy, and overall performance.

\section{References}

Alderfer, C. (1972). Existence, relatedness, \& growth. New York: Free Press.

ChangingMinds.org. (2002). Maslow's Hierarchy. Retrieved Sept. 10, 2005 from http://changingminds.org/explanations/needs/maslow.htm

Deci, E. L. (1975). Intrinsic motivation. New York: Plenum Press.

Deci, E. L., Vallerand, R. J., Pelletier L. G. \& Ryan, R. M. (1991). Motivation and education: The selfdetermination perspective. Educational Psychologist, 26, 325-346. 
Downes, S. (2005). Learning objects. Retrieved Sept. 5, 2005 from http://www.downes.ca/files/Learning_Objects.htm

Festinger, L. (1957). A theory of cognitive dissonance. Stanford, CA: Stanford University Press

Heylighen, F. (1993). Epistemology, introduction. Principia Cybernetica. Retrieved Sept. 12, 2005 from http://pespmcl.vub.ac.be/EPISTEMI.html.

Jochems, W., Van Merrienboer, J, Koper, R., \& Van Merrienboer, J. G. (2003). Integrated E-Learning: Pedagogy, technology, and organization (Open and Flexible Learning Series). NY: Kogan Page.

Leslie, S. (2005). EdTechPost. Retrieved Sept. 5, 2005 from http://www.edtechpost.ca/mt/archive/cat_learning_objects.html

Maslow, A. (1943). A theory of human motivation, Psychological Review, 50, 370-96.

McClellan, J. (2005). Tag team. The Guardian Unlimited: Technology. Feb. 3, 2005. Retrieved Dec. 19, 2005 from http://technology.guardian.co.uk/online/story/0,3605,1403974,00.html.

McClelland, D. C. (1975). Power: The inner experience. New York: Irvington.

McClelland, D. C., \& Burnham, D. H. (1976). Power is the great motivator. Harvard Business Review, 54(2), 100-110.

McGreal, R. (2004). Learning objects: A practical definition. Retrieved Sept. 5, 2005 from http://www.itdl.org/Journal/Sep_04/article02.htm

McLaren, I. (2004). New trends in web-based learning: Objects, repositories and learner engagement. European Journal of Engineering Education, 29(1), 65-71.

Nash, S. S. (2005). Social impact "Serious Games" and online courses. Retrieved Sept. 5, 2005 from http://www.xplanazine.com/archives/2005/06/social_impact_a.php

Siemens, G. (2003). Content management. Retrieved Sept. 5, 2005 from http://www.elearnspace.org/Articles/contentmanagement.htm

Smith, T., \& Korevaar, D. (2002). The Well-Tempered Clavier. Johann Sebastian Bach: Thirty-Seven Fugues and Select Preludes. Retrieved Sept. 9, 2005 from http://jan.ucc.nau.edu/ tas3/wtc.html.

Tetlock, P. E., \& Kim, J. (1987). Accountability and judgment in a personality prediction task. Journal of Personality and Social Psychology: Attitudes and Social Cognition, 52, 700-709.

Villano, M. (2005, September 1). Digital Libraries >> “Opening” a Digital Library. Campus Technology. Retrieved Sept. 15, 2005 from http://www.campus-technology.com/article.asp?id=11727

Von Glasersfeld, E. (1984). An introduction to radical constructivism. In P. Watzlawick, The Invented Reality, (pp.17-40). New York: W.W. Norton \& Company.

\section{Biography}

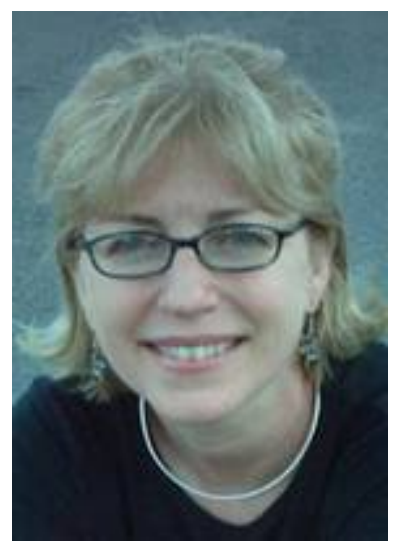

Susan Smith Nash has been involved in the design, development and administration of online courses and programs since the early 1990s. Her current research interests include the use of learning objects, new, popular technologies in distributed education, and leadership in e-learning organizations. Her articles and columns have appeared in journals, and her podcasts had weblog articles on e-learning can be found online in educational weblogs. She received her Ph.D. from the University of Oklahoma in 1996, and in addition to e-learning, Nash has also been involved in international economic development training, and humanities and culture. Her latest book, Lonelyhearts Pawn Shop, was published by Light \& Dust Books. Her book, Leadership in the e-Learning Organization, is forthcoming. 